\title{
RESIDUOS SOLIDOS
}

\section{SITUAÇÃO DOS RESIDUOS SOLIDOS ENCONTRADOS EM ATERROS SANITARIOS E LIXÕES NO BRASIL}

\author{
Marcos Vinicius da Silva Lima'__marcosvinilimasilva@ hotmail.com \\ ${ }^{1}$ Graduando do curso de Engenharia Ambiental, Instituto Federal da Bahia.
}

\begin{abstract}
Resumo: Com o objetivo de evidenciar a problemática da situação dos resíduos sólidos encontrados nos diversos lixões e aterros sanitários vistos no País, mesmo com a promulgação da Política Nacional dos Resíduos Sólidos, A Lei N ${ }^{\circ}$ 12305/ 2010, muitos lixões ainda continuam a existir na maioria dos municípios brasileiros sem qualquer tratamento e em suma a céu aberto. A pesquisa foi feita com base na necessidade de se evidenciar a precariedade no combate do descarte consciente de lixo em sua totalidade, enquadrada e etapas, que vai desde a chegada a sua reutilização, se dando de forma cíclica. De acordo com o Ministério do Meio Ambiente cerca de 33\% das cidades afirmam ter aterros sanitários, um dado alarmante que se dá paralelo a esse dado é que, em todas as regiões do País, até mesmo os que possuem aterro, sofrem com a disposição irregular de resíduos sólidos. A crise econômica consegue agrava a catástrofe exposta pela precariedade no tratamento de resíduos sólidos, que se atrelam a terceirização da titulação, demonstrando a importância do Estado tomar partido desses processos produtivos, mas a inadimplência se dá em toda a Nação, de metrópoles a cidades de menor porte. Os processos de emprego que se cresce no Brasil e que no resto do mundo já se dá de maneira normal. $\mathrm{O}$ biodigestor que se associa a diversos resíduos sólidos, reaproveitando grande parte dos compostos encontrados nos efluentes, em contrapartida a isso se vem no investimento, onde o empecilho se torna vilão na inserção inerente dessa solução.
\end{abstract}

\section{INTRODUÇÃO/OBJETIVO}

\begin{abstract}
A Associação Brasileira de Normas Técnicas - ABNT, define resíduos como os "restos das atividades humanas, considerados pelos geradores como inúteis, indesejáveis ou descartáveis, podendo apresentar se no estado sólido, semissólidos ou líquido, desde que não seja passível de tratamento convencional" (ABNT, 2004).Os resíduos sólidos são classificados segundo a lei 12305/10 em: resíduos domiciliares, de limpeza urbana, de estabelecimentos comerciais e prestadores de serviço, industriais, de serviços da saúde, da construção civil e de mineração.
\end{abstract}


Os resíduos sólidos no Brasil vem se evidenciando como um fator negativo atual e futuramente já que não é dado a devida destinação, o que se leva à tona diversos fatores do Estado e Sociedade Civil, a legislação do País pode ser consideração teoricamente como um modelo para o resto do mundo, em controvérsia a situação real não se pode leva em consideração essa afirmação anterior, pois a falta de vontade política e ausência da rigidez no comprimento da lei faz com que esse fato se torne mais normal que a própria efetivação , no âmbito populacional se dá a pouca conscientização quanto a importância da educação ambiental e como isso pode afeta o equilíbrio climático, geológico e entre outros, enfim , o mal gerenciamento dos recursos naturais e financeiros demandam hoje em dia alguma solução que diminua os impactos ocorridos.

A forma que pode minimizar esta problemática é a biodigestão de resíduos sólidos nos diversos âmbitos desde o campo até as cidades no saneamento total e individual. A sua função basilar é destinado para a produção de biofertilizante e biogás, relacionado a situação do País é necessário entender que o potencial energético da produção dos resíduos sólidos é enorme e além do potencial são os benéficos acarretados com isso.

O processo de digestão anaeróbica faz com que com pouco ou nenhum oxigênio as bactérias e microrganismos, fazendo a fermentação dos efluentes e assim gera diversos compostos das mais variadas funções a partir do que foi anteriormente dito, o intuito é melhorar o mapa do saneamento do Brasil, pode-se usar como exemplo a cidade de Franca em SP que consegue tratar quase que todo o saneamento da cidade, conseguindo fazer com que o ciclo natural da reutilização da agua se dê muito bem.

\section{METODOLOGIA}

A pesquisa se dá a partir de referenciais bibliográficos, aliando os diversos âmbitos do conhecimento ambiental, na busca de entender os fatores que interferem toda a problemática que são os resíduos sólidos no Brasil. Foram mencionados nos diversos meios de comunicação como a tv e a internet, há de se levar em consideração estudos que foram já realizados e aliar esses antigos resultados com o mapa do saneamento básico atual, conseguindo assim um resultado que determine o contexto da obtenção dos parâmetros a serem seguidos a frente. A Política Nacional dos Resíduos Sólidos, é tomada como modelo para o início da pesquisa, em decorrência do uso desse mecanismo, aliando o conhecimento cientifico com as diretrizes e leis vigentes que relacionam toda a questão ambiental com ênfase nos resíduos, que são tema de recorrentes artigos, evidenciando a situação periodicamente do mapa do País e todo o problema que isso acarreta tanto ao solo quanto, principalmente, ao desenvolvimento humano em suas diversas formas. Além disso, o problema econômico é fator importante, pelo fato da extensa lista de municípios que sofrem com o endividamento com empresas que gerem o sistema de lixos e efluentes gerados pela população, foi coletado em diversos artigos já realizados relacionados a resíduos sólidos e referencias em revistas e sites especializadas aliando pensamentos que aparentemente não convergentes, mas buscando formas de transparecer o mapa atual do sistema que integrar o saneamento que vem lixões e aterros sanitários e como isto pode ajuda com o tratamento a um potencial energético. 


\section{RESULTADOS E DISCUSSÕES}

Dados obtidos mostraram que o mapa do saneamento se dá muito discrepante em relação a distribuição gradual da coleta dos resíduos. O ministérios das Cidades publicou em 2014 um mapa do manejo dos resíduos sólidos, esse documento relata a situação desses efluentes no País, essa pesquisa reuniu cerca de $70 \%$ dos municípios, onde diagnostica os pontos mais relevantes. Já a amazonfort delatou que em 2013 dentre 3000 que vou visto lixões ou aterros sanitários só existia a coleta de lixo em 900 delas, é de suma importância a constatação da precariedade do tratamento e destinação dos resíduos, numa Nação onde ainda há fome e que o índice de desperdício tanto de resíduos orgânicos quanto dos demais geram muitos detritos acumulados e toda essa gama que varia de lixos eletrônicos, hospitalares onde a meia-vida deles podem se perpassar por muitos anos, não são separadas e reaproveitadas da forma certa e na importância devida, já que alguns elementos químicos são de risco eminente tanto pra população quanto para o solo, podendo penetrar os lençóis freáticos e assim alterar o ciclo biogeoquímico do solo. 


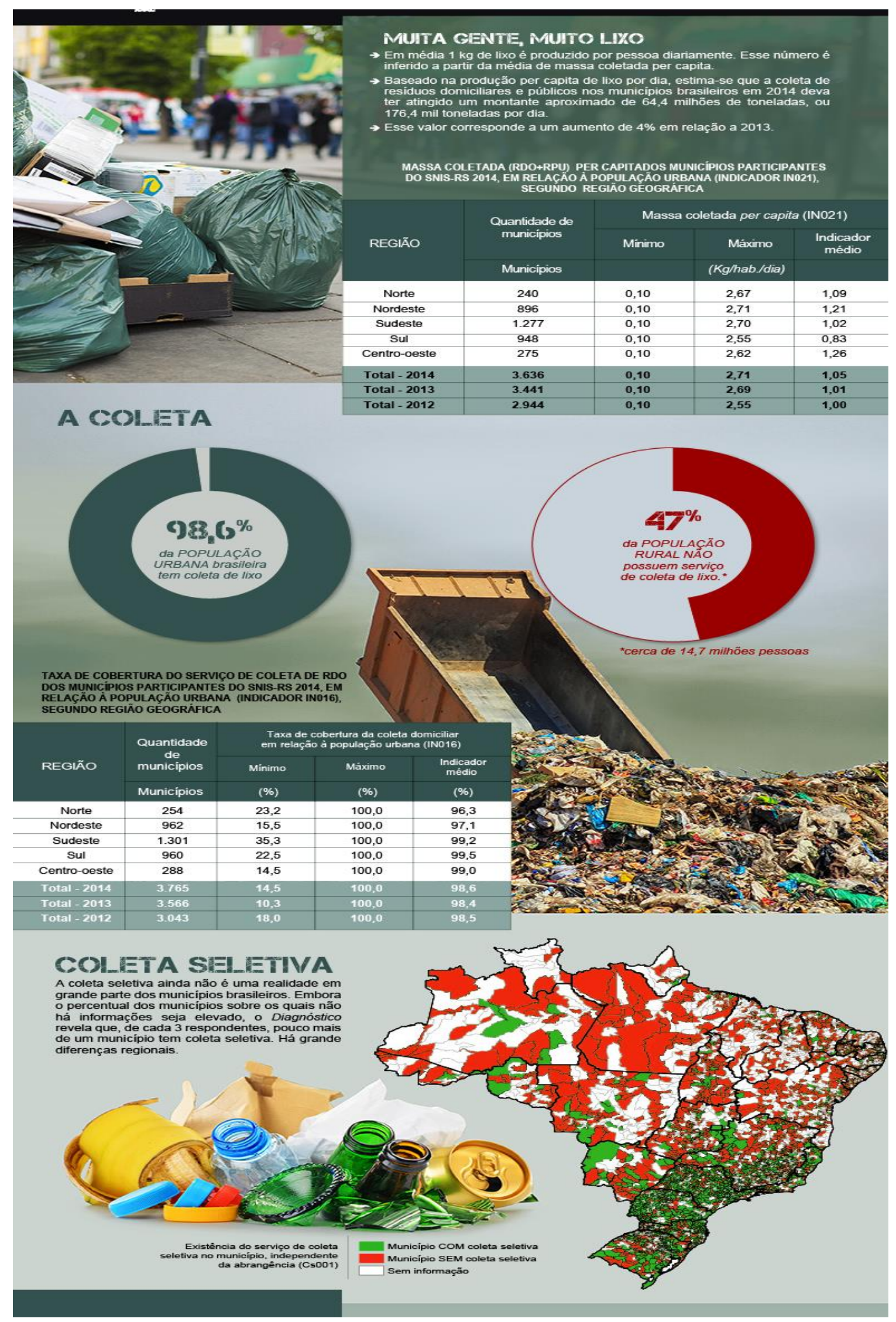

Fonte: Revista Pré-univesp, Ministério das Cidades 2014 
Na busca de melhorar essa questão em relação ao destino de matérias descartados de forma errada o biodigestor aparece como forma de reaproveitamento energético, tornando mais eficaz o descarte desses resíduos e diminuindo os custos nas diversas formas, podendo chegar a uma produção em larga escala.

Assim, se apresenta uma nova forma de tratar esses resíduos, na obtenção de novas vagas de empregos e na diminuição da poluição a partir do gás metano $(\mathrm{CH} 4)$.

Implementando a pratica de preservação do solo e aproveitamento do potencial energético encontrado nos lixões espalhados pelo território nacional e entra como processo que ajude melhorar o saneamento de residências e mostrando uma oportunidade de destino melhor a esses dejetos.

Usando do seu potencial energético e da reutilização consciente de todo os resíduos domésticos, industrias e rurais depositados nestes locais. Na busca de revitalizar os planos de gestão integrada de resíduos sólidos, buscando estimar de forma melhor a quantidade de lixo produzido, trabalhando na sua reutilização.

\section{CONCLUSÕES/RECOMENDAÇÕES}

Como evidenciado no decorrer do trabalho, o problema da falta de tratamento dos resíduos sólidos no Brasil é algo muito preocupante e alarmante e pode ser fixado desde a introdução a problematização do não uso dos recursos públicos de forma pertinente em relação a este tema e toda a perca de um futuro potencial energético encontrado nos resíduos. O material de estudo foi encontrado de forma simples, já que é um tema de muita discussão nas diversas esferas da sociedade atual desde a cientifica na busca de diminuir o impacto como na sociedade civil, tendo em vista que a coleta seletiva aliada a educação ambiental podem ajudar a minimizar em escala domestica os resíduos descartados.

\section{REFERENCIAS BIBLIOGRAFICAS}

Situação dos Resíduos Sólidos no Brasil e no Mundo

<https://www.portaleducacao.com.br/conteudo/artigos/biologia/situacao-dos-residuossolidos-no-brasil-e-no-mundo/31502>. Acesso em: 29/05/2017

SITUAÇÃO ATUAL DOS RESÍDUOS SÓLIDOS NO BRASIL

$<$ http://www.portalresiduossolidos.com/situacao-atual-dos-rs-no-brasil/>. Acesso em: $28 / 05 / 2017$ 
Situação atual dos resíduos sólidos no Brasil

http://amazonfort.com.br/geral/situacao-atual-dos-residuos-solidos-no-brasil/> Acesso em: 06/06/2017

RESÍDUOS SÓLIDOS NO BRASIL

Diagnóstico do Manejo de Resíduos Sólidos Urbanos traz um retrato da coleta e destinação de lixo no Brasil

<http://pre.univesp.br/residuos-solidos-no-brasil\#.WTdWRUUrLIV>

Acesso em: 30/05/2017 